\title{
Anti-Tumor Effect and Mechanism of Parthenolide in Gastric Cancer Cellline BGC-823
}

\author{
Wenhao Zhu, Hanni Zhang, Yunliang Guo, Keli Ge, Yonghong Zhou* \\ Institute of Integrative Medicine, Medical College, Qingdao Universtiy, Qingdao, China \\ Email: ^690415496@qq.com
}

How to cite this paper: Zhu, W.H., Zhang, H.N., Guo, Y.L., Ge, K.L. and Zhou, Y.H. (2019) Anti-Tumor Effect and Mechanism of Parthenolide in Gastric Cancer Cellline BGC-823. Open Access Library Journal, 6: e5271.

https://doi.org/10.4236/oalib.1105271

Received: February 20, 2019

Accepted: March 5, 2019

Published: March 8, 2019

Copyright () 2019 by author(s) and Open Access Library Inc.

This work is licensed under the Creative Commons Attribution International License (CC BY 4.0).

http://creativecommons.org/licenses/by/4.0/

(c) (i) Open Access

\begin{abstract}
Objective: To study the anti-tumor effect and mechanism of parthenolide in gastric cancer cell BGC-823. Methods: The cck8 assay was used to detect the changes of BGC-823 cells viability after treatment with different concentrations of parthenolide at different time points. The proliferation ability of BGC-823 cells was detected by clone formation assay. And the cell cycle and apoptosis were measured by flow cytometry. Meanwhile, to detect the difference in intracellular ROS production levels, the fluorescence assay was used. And with the help of western blotting, cell cycle- and apoptosis-related protein expression can be detected. Results: Parthenolide could inhibit the viability of BGC-823 cells in a dose- and time-dependent manner $(P<0.01)$. In BGC-823 cells exposed to parthenolide, the apoptosis rate was found significantly increased $(P<0.01)$, and the protein expression of cleaved-caspase3, cleaved-caspase8, and cleaved-caspase9 significantly increased $(P<0.01)$; the cell cycle was arrested at G1phase $(P<0.01)$; the protein levels of CyclinD1 and CyclinE1 decreased $(P<0.01)$, and the expression of $\mathrm{P} 53$ and $\mathrm{P} 21$ protein increased $(P<0.01)$; massive intracellular ROS generation was found $(P<$ $0.01)$. Furthermore, the nuclear protein levels of c-Myc, E2F1, and NF- $\kappa \mathrm{B}$ and the protein level of phosphorylated STAT3 decreased in BGC-823 cells exposed to parthenolide $(P<0.01)$. Conclusion: Parthenolide may inhibit the proliferation of BGC-823 cells and induce G1-phase cell cycle arrest and apoptosis via inhibiting STAT3-c-Myc-E2F1 axis.
\end{abstract}

\section{Subject Areas \\ Internal Medicine, Oncology}

\section{Keywords}

Parthenolide, Gastric Cancer, Cell Proliferation, Cell Cycle, Apoptosis 


\section{Introduction}

Gastric cancer is a malignant tumor originating from the gastric mucosal epithelium. It is one of the most common malignant tumors in the world. The prognosis is relatively poor, which seriously threatens human health [1]. China is a country with high incidence of gastric cancer, with morbidity and mortality accounting for about $50 \%$ of the world [2]. The diseased cells of gastric cancer generally appear in the inner layer of the stomach, mostly due to ulcers, and most of the cancer spreads along the stomach wall to form tumors. In China, the status quo of gastric cancer treatment presents a phenomenon of one high and three low: high mortality rate, low early diagnosis rate, low surgical cure rate, low five-year survival rate [2]. But existing treatments fail to achieve the desired results. Therefore, it is urgent to open up new ideas and methods for the research and treatment of gastric cancer. In the past studies of traditional medicine and modern medicine, a pure extract obtained from the geranium germ of the Compositae-parthenolide, shows effective anticancer activity [3].

Parthenolide (PN) is an important component of sesquiterpenes (SLs) [4] [5]. PN was first proven to have anti-tumor properties in 1973 [6]. These biological properties of $\mathrm{PN}$ can be attributed to its strong inhibition of nuclear factor NF- $\kappa \mathrm{B}$ and via the NF- $\kappa \mathrm{B}$ signaling pathway [7]. PN can also achieve its anti-tumor effect by blocking the binding of STAT-3 and STAT-1 to regulatory elements in DNA [8]. Oxidative stress refers to the state of the cells in which the production of reactive oxygen species (ROS) is increased or the function of the antioxidant defense system is impaired [9]. The intracellular redox state is the result of a precise balance between oxidative stress and the endogenous thiol buffer system [9]. However, many cancer therapeutics are actually apoptosis inducers, because they can destroy the intracellular thiol buffer system by eliminating or redistributing GSH, thereby destroying the redox balance [10]. Therefore, an imbalanced intracellular redox state triggers downstream cellular events leading to apoptotic cell death [11]. According to some studies, PN can increase the level of ROS production in tumor cells, thereby making it progress to cell death [12].

In this study, we investigated the anti-tumor effect of $\mathrm{PN}$ in gastric cancer cell line BGC-823. At the same time, it explains and proves this effect in the perspective of inducing apoptosis and cycle arrest. And found that the mechanism of this anti-tumor effect may be that the PN increases the level of intracellular oxidative stress, thereby inhibiting the downstream STAT3-c-myc-E2F1 signal transduction pathway, so as to increase the total apoptosis rate and block the cell cycle; ultimately, it inhibits gastric cancer cells.

\section{Materials and Methods}

\subsection{Material}

Cell source: The human gastric cancer cell line BGC-823 is provided by the National Cell Resource Center. 
Source of medicine: Parthenolide, molecular formula: $\mathrm{C}_{15} \mathrm{H}_{20} \mathrm{O}_{3}$, analytical standard, HPLC $\geq 99 \%$, molecular weight: 248.32 , supplied by Calbiochem, Germany. The DMSO solution was used to prepare a $200 \mathrm{mM}$ stock solution, which was stored at $-80^{\circ} \mathrm{C}$ for use, and thawed at $4^{\circ} \mathrm{C}$ before use.

\subsection{Method}

\subsubsection{Cell Culture}

Gastric cancer cell BGC-823 was obtained from National Infrastructure of Cell Line Resource (Beijing, China). All these cells were maintained under standard culture conditions $\left(37^{\circ} \mathrm{C}, 5 \% \mathrm{CO}_{2}\right)$ in RPMI 1640 Medium with 10\% FBS (Gibco).

\subsubsection{CCK-8 Cell Viability Assay}

To assess cellular viability, $1 \times 10^{4}$ cells were added to the wells of a 96-well plate. The different groups were pretreated with various concentration of $\mathrm{PN}(15,17.5$, $20,22.5$, and $25 \mu \mathrm{M})$. Each group occupied three wells on the plate. Viability of myocardiocytes was detected using the CCK- 8 assay after A/R. Briefly, in the absence of light, CCK-8 reagent $(10 \mu \mathrm{l})$ was added to each well and the plates were incubated at $37^{\circ} \mathrm{C}$ under an atmosphere of $5 \% \mathrm{CO}_{2}$ for $2 \mathrm{~h}$. Then, the optical densities were detected using a microplate reader.

\subsubsection{Colony Formation Assay}

BGC-823 cells were reseeded into 6-well plates at a density of 10,000 cells/well and incubated for 14 days. The cell culture medium was refreshed every three days. At the end of each experiment, the cells were fixed with $4 \%$ paraformaldehyde for $15 \mathrm{~min}$ and then washed with phosphate-buffered saline (PBS) and stained with $500 \mu \mathrm{l}$ of Giemsa for $30 \mathrm{~min}$. Cell colonies were photographed under an inverted microscope and cell colonies with $>50$ cells or more were counted. The experiment was in duplicate and repeated at least twice.

\subsubsection{Cell Cycle Assay}

The cells were harvested and washed in PBS before fixation in cold 70\% ethanol which was added drop wise to the pellet while vortexing. Cells were fixed for 30 $\min$ at $4^{\circ} \mathrm{C}$. Fixed cells were washed twice in PBS and spun at $250 \mathrm{~g}$ in a centrifuge. Cells were incubated with $50 \mu \mathrm{l}$ of a $100 \mu \mathrm{g} / \mathrm{ml}$ stock of RNase and $200 \mu \mathrm{l}$ Propidium Iodide (from $50 \mu \mathrm{g} / \mathrm{ml}$ stock solution). Flow cytometer was used to analyze the cell population for cell cycle changes (BD, USA).

\subsubsection{Cell Apoptosis Assay}

Annexin-V-FITC/PI apoptosis detection kit was used to detect the apoptosis of PN treated BGC-823 cells according to the manufacturer's instructions. The cells were seeded into 6 well plates with a density of $1 \times 10^{5}$ cells/well and incubated with parthenolide for $24 \mathrm{~h}$. After incubated with parthenolide, BGC-823 cells were harvested, washed triple with PBS, suspended in Annexin-V binding buffer, and incubated with FITC-labeled Annexin-V and PI for 5 min at room tem- 
perature in dark. Then, the samples were immediately analyzed by Flow cytometry (BD, USA).

\subsubsection{Determination of Intracellular ROS}

Dilute DCFH-DA in serum-free medium at 1:1000 to a final concentration of 10 $\mu \mathrm{mol} / \mathrm{L}$. Remove the cell culture medium and add the appropriate volume of diluted DCFH-DA. Incubate in a $37^{\circ} \mathrm{C}$ cell incubator for 20 minutes. The cells were washed three times with serum-free cell culture medium to fully remove DCFH-DA that did not enter the cells. ROS production levels are detected by fluorescence microscopy.

\subsubsection{Western Blot}

Collecting protein samples and determines the protein concentration of each protein sample. The SDS-PAGE gel was configured and loaded for electrophoresis. After the electrophoresis is finished, the film is transferred by semi-dry method. The PVDF membrane was immersed in a TBST blocking solution containing $100 \mathrm{~g} / \mathrm{L}$ skim milk powder for $1 \mathrm{~h}$ at room temperature. Prepare primary antibody dilution (1:1000) with 5\% BSA in TBST solution and incubate overnight at $4^{\circ} \mathrm{C}$ shaker. Incubation with HRP-labeled secondary antibody dilution (1:2000) is for $2 \mathrm{~h}$ at room temperature.

\subsubsection{Statistical Analysis}

The experimental data were analyzed by SPSS17.0 software. The data was first tested for normality and homogeneity of variance. The results were expressed by $\left(\begin{array}{ll}\bar{X} & \pm s\end{array}\right)$. The differences between groups were compared by One-Way ANOVA. The pairwise comparison was analyzed by t test. $P<0.05$ was considered statistically significant.

\section{Result}

\subsection{PN Causes Morphological Changes in BGC-823 and Reduce Cell Viability}

Under light microscopy, the gastric cancer cells in DMSO group have clear morphology and good adherence; In PN treated group, the BGC-823 shrink in size, the cell membrane shrinks and ruptures, and the cells die in a large area (Figure 1(a)). The experimental results show that PN can inhibit the viability of gastric cancer cell line BGC-823, and the inhibitory effect increases with the increase of concentration and treatment time. There were significant differences between the two groups at each concentration and time $(F$ (concentration) $=$ 920.9, $P<0.01 ; F$ (time) $=100.9, P<0.01 ; F$ (interaction $)=59.29, P<0.01)$ (Figure 1(b)).

\subsection{PN Inhibits the Proliferation of BGC-823}

The number of cell colonies decreased with increasing concentration of PN treatment. It indicated that PN can inhibit the proliferation of BGC-823 cells. 


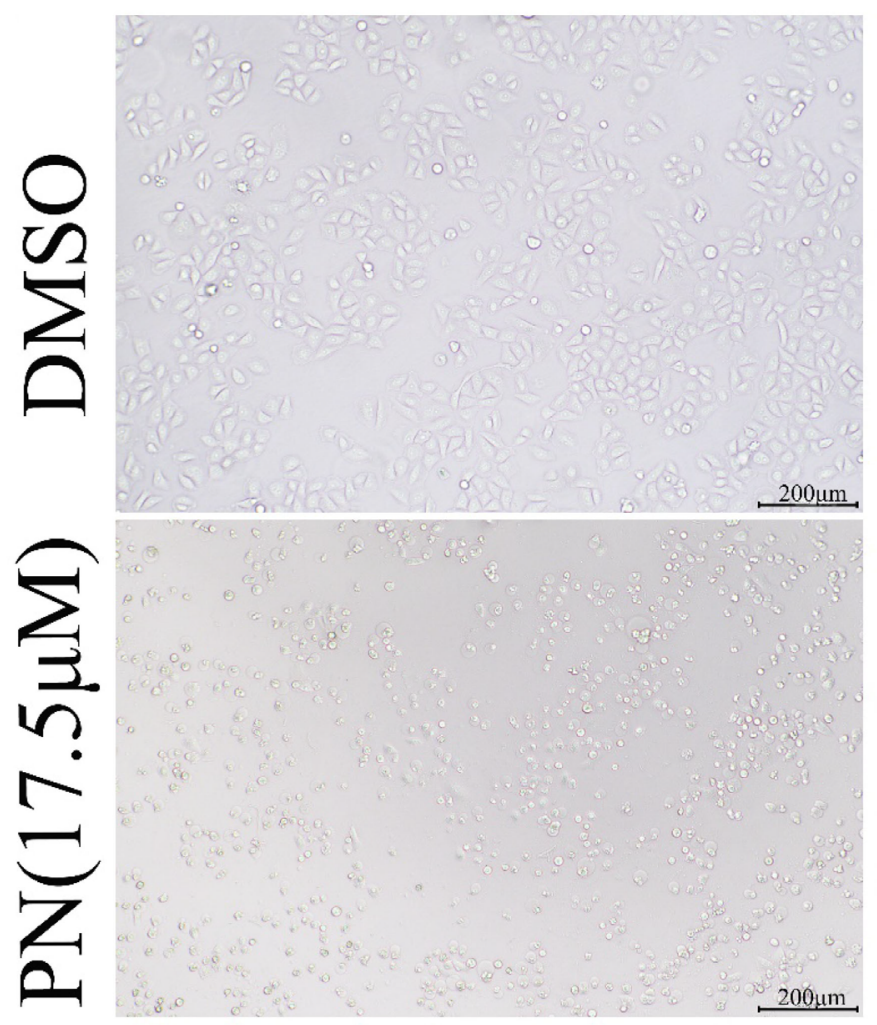

(a)

\section{BGC-823}

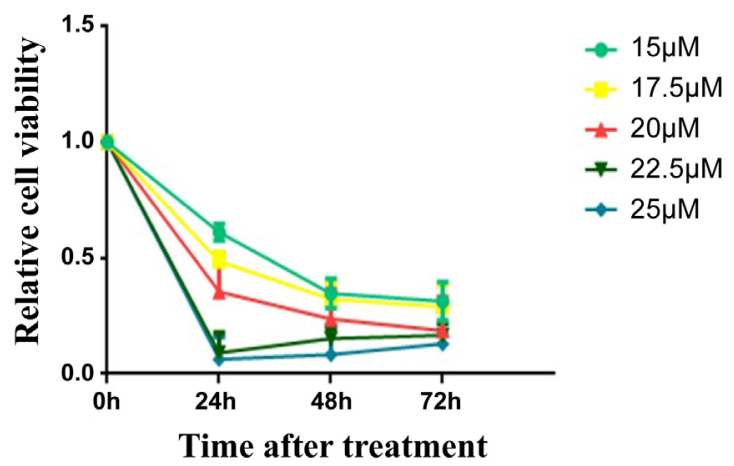

(b)

Figure 1. (a) Changes in cell morphology after $\mathrm{PN}$ treatment under light microscope $(\times 200, \mathrm{PN} / 17.5 \mu \mathrm{M} / 24 \mathrm{~h})$; (b) CCK-8 assay for PN on gastric cancer cell BGC-823 Inhibition of viability.

The number of colony decreased as the concentration of PN increased (Figure 2(a)). This indicates that PN could inhibit the proliferation of gastric cancer cell line BGC-823, and with the increase of concentration, the cell proliferation ability tends to decrease. The concentration of PN treated group and DMSO group are significantly different $(F=312.6, P<0.01)$ (Figure 2(b)).

\subsection{PN Can Cause Cycle Arrest of BGC-823}

As shown in Figure 3(a), the green part is the S phase, the blue-violet part is the 


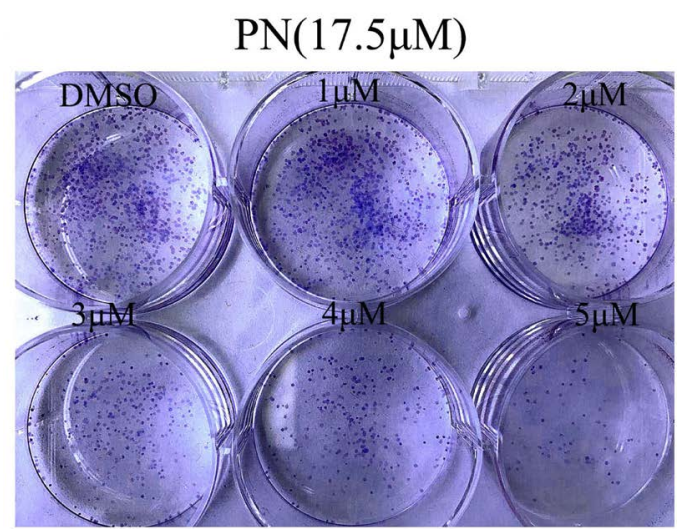

(a)

BGC-823

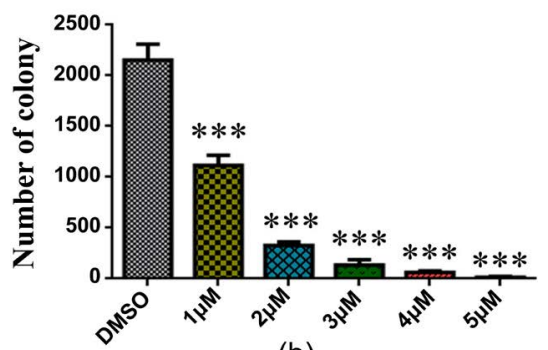

(b)

Figure 2. Clonal formation assay for inhibition of PN on the proliferation of gastric cancer cell line BGC-823. ${ }^{\star * *} P<0.001$ compared with DMSO group.
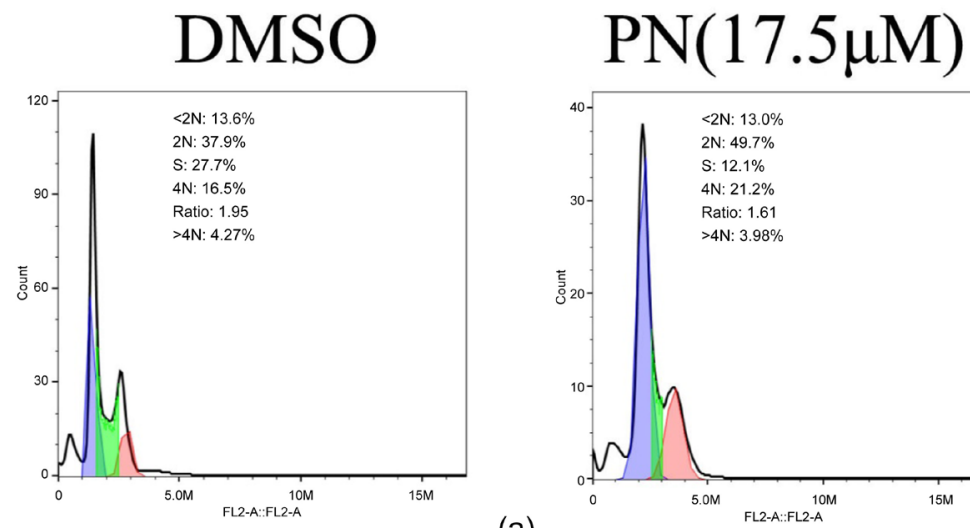

(a)
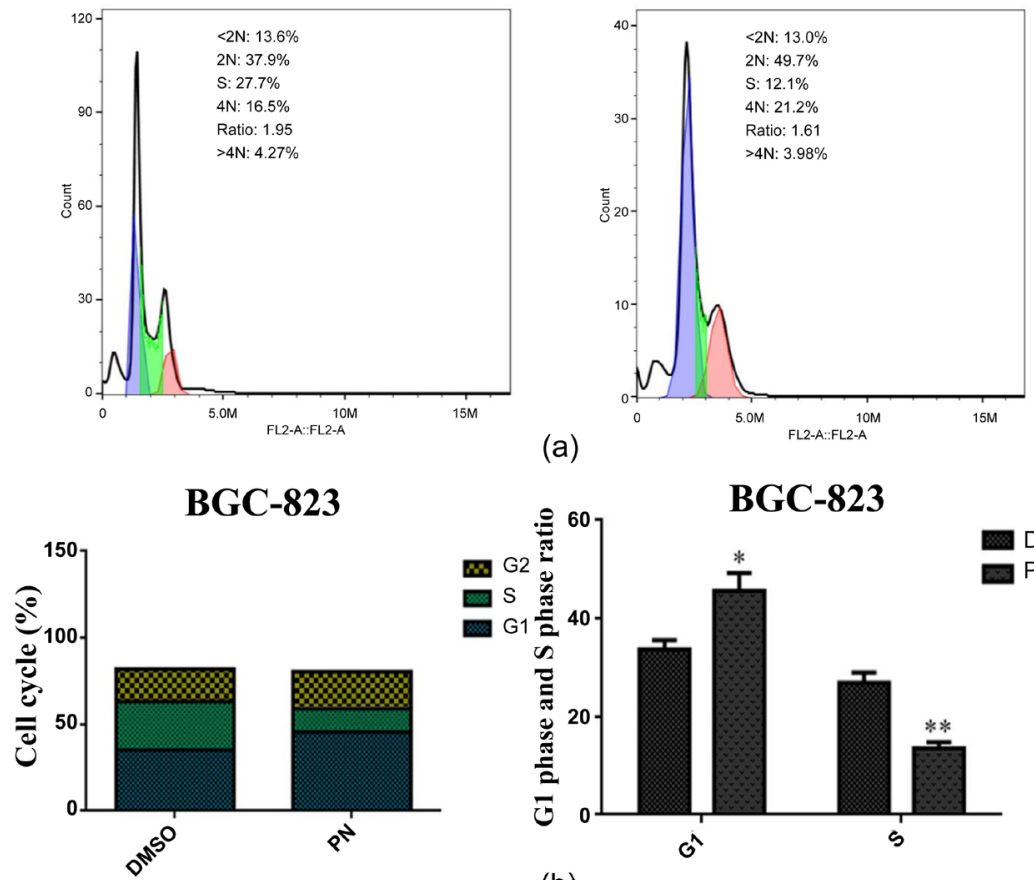

(b)

Figure 3. PI single staining assay detects the effect of PN on cell cycle arrest in gastric cancer cell line BGC-823; the green part is S phase and the blue-violet part is G1 phase. ${ }^{\star} P$ $<0.05,{ }^{* *} P<0.01$ compared with DMSO group. 
G1 phase, and the red part is the G2 phase. The S phase of the PN group was shortened and the G1 phase was prolonged, that is, the cell cycle was arrested at the G1phase. At the same time, the statistical results are also displayed. In the PN treated group, the $S$ phase of gastric cancer cells was shortened and the G1 phase was prolonged, which was statistically significant compared with the DMSO group (G1 phase: $t=4.216, P<0.05$; S phase: $t=7.443, p<0.01$ ) (Figure 3(b)).

\subsection{PN Can Induce Apoptosis in BGC-823}

Annexin-V+PI double staining method was used to detect the effect of PN on apoptosis in BGC-823. Annexin-V positive cells were apoptotic cells in the right two quadrants. The statistical results showed that the apoptosis rate of $\mathrm{PN}$ treated group was significant. The increase was statistically significant compared with the DMSO group $(t=27.57, P<0.01)$, PN induced apoptosis in BGC-823 (Figure 4(a)). And the same result was observed under a fluorescence microscope, and the red and green fluorescence of the PN treated group was significantly enhanced compared with the DMSO group (Figure 4(b)).

\subsection{PN Can Cause an Increase in the Level of ROS Production in BGC-823}

Cytofluorescence assay was used to detect the effect of PN on the induction of

(a)

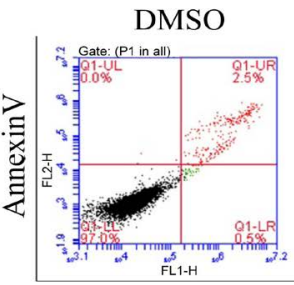

(b)

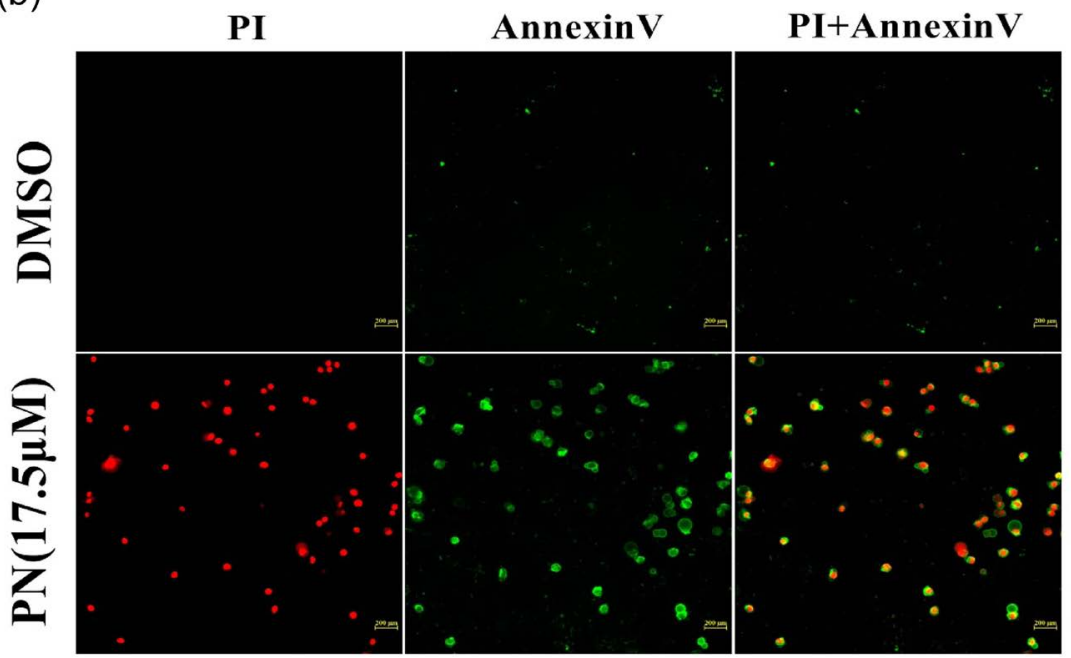

Figure 4. Annexin-V+PI double staining assay and fluorescence microscope detects the effect of PNon apoptosis in gastric cancer cell line BGC-823 $(\times 200){ }^{* * *} P<0.001$ compared with DMSO group. 
ROS production in BGC-823 (PN/17.5 $\mu \mathrm{M} / 24 \mathrm{~h})$. The experimental results showed that compared with the DMSO group, the green fluorescence intensity and number of the PN treated group increased significantly, and the difference was statistically significant $(t=10.92, P<0.01)$. This indicates that PN can induce an increase in the level of ROS production in BGC-823 (Figure 5).

\subsection{PN Can Cause Cycle-Related and Apoptosis-Related Protein Levels in BGC-823}

The results showed that PN $(17.5 \mu \mathrm{M})$ could decrease the total protein levels of CyclinD1 $(F=159.4, P<0.01)$ and CyclinE1 $(F=25.40, P<0.01)$ in gastric cancer cell line BGC-823, and make P53 $(F=53.74, P<0.01)$, P21 $(F=73.03, P<$ $0.01)$, the total protein level increased, and the difference was significant compared with the DMSO group, which was statistically significant. This is consistent with the PN shown by the flow cycle results that the cell cycle is arrested in the G1 phase. In addition, we also studied the apoptosis-related proteins caspase3, caspase8 and caspase9, and found that the cleaved cleaved-caspase $3(F=$ 2024, $P<0.01)$, cleaved-caspase8 $(F=228.1, P<0.01)$, and cleaved9 $(F=241.1, P$ $<0.01)$ increased, which was also statistically different from the DMSO group. This is consistent with the increase in apoptotic rate as shown by the results of the Annexin-V+PI double staining method (Figure 6).

The results showed that PN $(17.5 \mu \mathrm{M})$ could make c-Myc $(F=306.9, P<$ $0.01)$, E2F1 $(F=1067, P<0.01)$ and NF- $\kappa \mathrm{B}$ in the nucleus of gastric cancer cell line BGC-823. The protein level of $(t=8.72, P<0.01)$ was decreased, and the total protein level of STAT3 was unchanged and the protein level of p-STAT3 ( $t=$ 9.148, $P<0.01)$ decreased. The difference was statistically significant compared with the DMSO group (Figure 7).

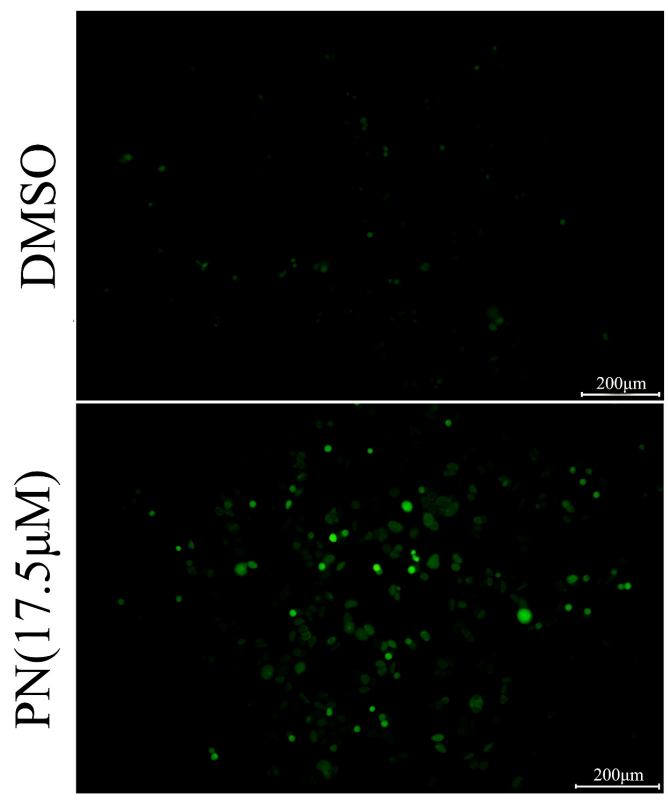

Figure 5. Cellular fluorescence assay to detect the effect of PN ( $24 \mathrm{~h})$ on ROS production in gastric cancer cell line BGC-823 $(\times 200)$. 


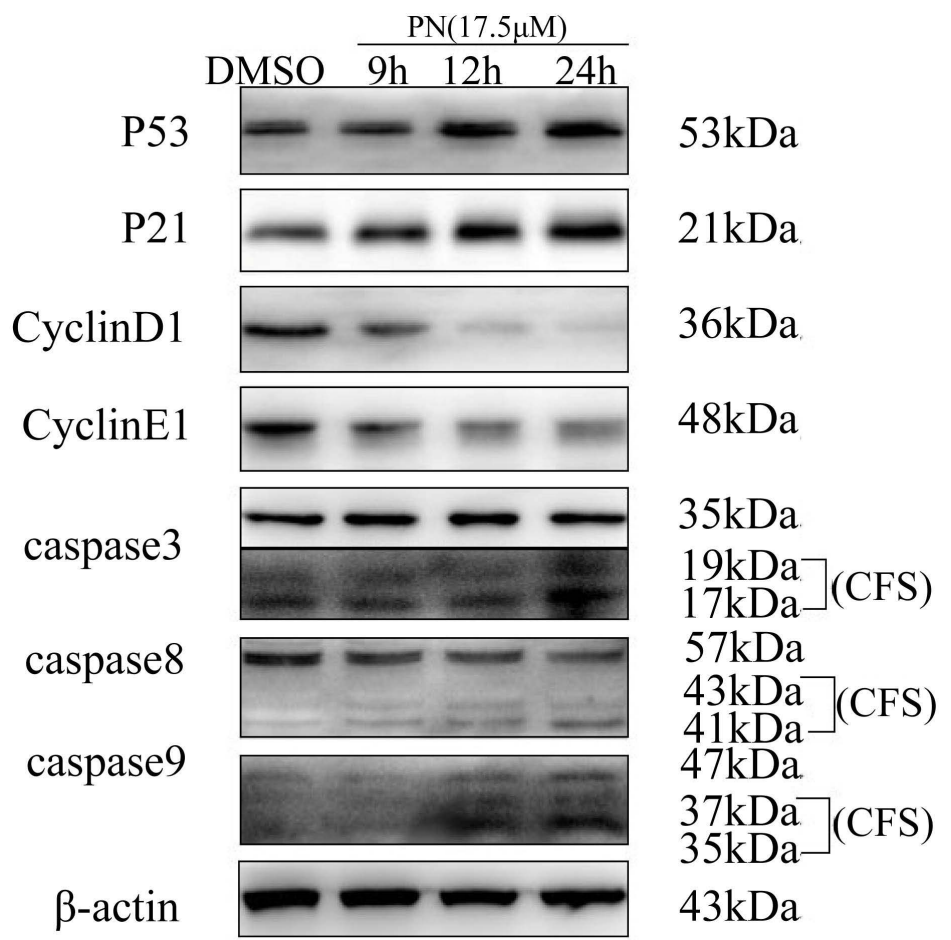

Figure 6. Western blot analysis of $\mathrm{PN}(17.5 \mu \mathrm{M})$ treatment of gastric cancer cells BGC-823 at different time periods and changes in total protein levels of apoptosis-related molecules (CFS: cleaved forms).

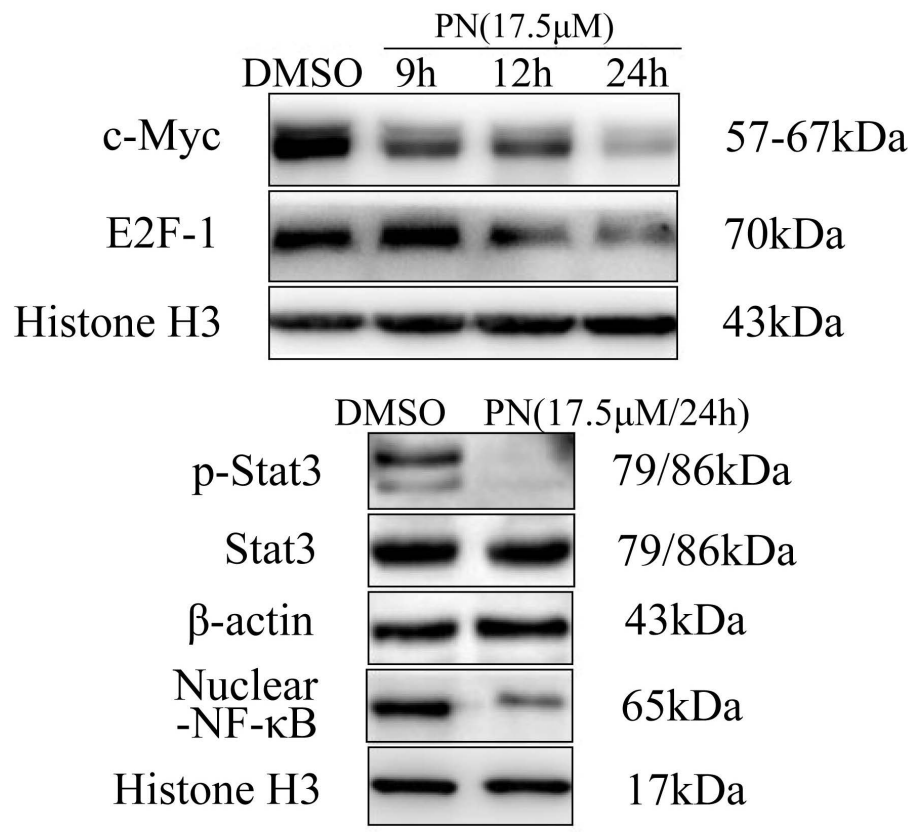

Figure 7. Western blot analysis of nucleoprotein c-Myc, E2F1 and NF- $\kappa$ B, STAT3 phosphorylation and total protein levels in gastric cancer cells BGC-823 treated with PN (17.5 $\mu \mathrm{M})$.

\section{Discussion}

A large number of previous studies have shown that $\mathrm{PN}$ has anti-tumor effects in 
a variety of tumors [13]. The role of $\mathrm{PN}$ in gastric cancer is rarely reported. In this study, it was found by CCK- 8 that PN can effectively inhibit cell viability in BGC-823, and the inhibitory effect increases with the increase of its concentration and treatment time, and the inhibitory effect of PN on gastric cancer cells is preliminarily proved.

In cell death, apoptosis plays a very important role, so we investigated whether PN can induce apoptosis in BGC-823 cells. The results of Annexin-V+PI double staining flow test showed that the total apoptosis rate of BGC-823 cells increased after PN treatment, which indicated that it could induce apoptosis in BGC-823. We further examined the expression of apoptosis-related proteins. A series of caspase cascade activation is a very important step in Fas-induced exogenous apoptosis [14], in which caspase- 8 activation is the first step, and activated caspase- 8 triggers downstream caspase- 9 and caspase- 3 activation [15]. Caspase- 3 is a key enzyme in apoptosis. Once activated, a downstream cascade occurs, making apoptosis inevitable [16]. This study found that after PN treatment of BGC-823, caspase8, caspase 9 and caspase 3 splicing protein levels increased significantly with increasing treatment time, indicating that $\mathrm{PN}$ induced exogenous apoptosis in BGC-823 [17].

In addition, cell cycle arrest also plays an important role in the upstream factors that induce apoptosis. A number of reports have revealed that PN can cause apoptosis by inducing cell cycle arrest [18]. The PI single-staining experiment showed that the proportion of G1 phase of BGC-823 cells in PN treatment group was significantly increased, and the proportion of $S$ phase was significantly decreased. This indicates that PN can block the cell cycle of BGC-823 in G1 phase. We further examined the expression of cell cycle-associated proteins. When the chromosomal DNA of the cell is damaged, P53 binds to the corresponding part of the DNA and acts as a special transcription factor [19], which activates p21 transcription [20]. In the present study, we found that the total protein levels of BGC-823 cell cycle inhibitory regulatory proteins P21 and P53 are elevated after PN treatment, and multiple Cyclin-CDK complexes bind to P21 and inhibit the corresponding protein kinase activity [21]. At the same time, the experimental results showed that the total protein levels of the cell cycle-promoting regulatory proteins CyclinD1 and CyclinE1 were decreased, which also proved that the treatment of PN caused G1 arrest of its cell cycle.

Moreover, elevated levels of intracellular ROS production play a key role in the initial stage of cell death, causing oxidative stress, leading to cell death including apoptosis [10]. This study found that the level of ROS production in BGC-823 was improved after PN treatment. This suggests that PN may induce apoptosis by inducing ROS production in BGC-823.

Finally, we screened some upstream protein molecules related to apoptosis of gastric cancer cells to explore the mechanism of $\mathrm{PN}$-induced apoptosis in gastric cancer cell line BGC-823. According to previous studies, the anti-tumor mechanism of PN includes NF- $\kappa \mathrm{B}, \mathrm{JAK} / \mathrm{STAT}$ and MAPK/ERK signaling pathways 
[22] [23] [24]. c-Myc gene is involved in both cell dying and development of various tumors. When c-Myc gene expression is down-regulated, cells stop in G1 phase and stop proliferating; when c-Myc expression is enhanced, it will promote cell malignant transformation. Lead to the occurrence of tumors [25]. $\mathrm{E} 2 \mathrm{~F} 1$ is one of the transcription factors. This protein has an additional cyclin-binding domain. The decrease in expression can block the cell cycle from G1 to $S$ phase and inhibit cell proliferation [26]. Moreover, E2F1 has a synergistic effect with c-Myc. E2F1 has been confirmed as a target gene of c-Myc, which can reduce the expression of c-Myc by down-regulating E2F1, thereby inhibiting the proliferation of tumor cells [27]. The results of this study showed that the protein levels of c-Myc, E2F1 and NF- $\kappa$ B in BGC-823 cells decreased after PN treatment. Moreover, studies have shown that the STAT3 signaling pathway may be involved in the regulation of c-Myc expression [28]. In normal cells, STAT phosphorylation is transient, and in many cancer cell lines or in primary tumors, STAT3 is continuously phosphorylated [29], becoming an activated transcription factor activation form, entering the nucleus and binding to target genes. Promote its transcription [30]. The results showed that the STAT3 phosphorylation was decreased, indicating that PN can block the phosphorylation of STAT3, thereby preventing its entry into the nucleus. This result is consistent with the results of studies in a variety of tumor cell lines, suggesting that PN may exert its anti-tumor effect in BGC-823 by inhibiting STAT3-c-Myc-E2F1 cascade.

\section{Conclusion}

PN has obvious cytotoxic effect in gastric cancer cell line BGC-823, which increases with does and time of action. This effect is induced by ROS production, G1 arrest and cell apoptosis in BGC-823 cells.

\section{Conflicts of Interest}

The authors declare no conflicts of interest regarding the publication of this paper.

\section{References}

[1] Torre, L.A., Bray, F., Siegel, R.L., et al. (2015) Global Cancer Statistics, 2012. CA: $A$ Cancer Journal for Clinicians, 65, 87-108. https://doi.org/10.3322/caac.21262

[2] Chen, W.Q., Zheng, R.S., Baade, P.D., et al. (2016) Cancer Statistics in China, 2015. CA: A Cancer Journal for Clinicians, 66, 115-132. https://doi.org/10.3322/caac.21338

[3] Jin, X., Zhou, J., Zhang, Z. and Lv, H. (2018) The Combined Administration of Parthenolide and Ginsenoside CK in Long Circulation Liposomes with Targeted tLyp-1 Ligand Induce Mitochondria-Mediated Lung Cancer Apoptosis. Artificial Cells, Nanomedicine, and Biotechnology, 11, 1-12.

[4] Wang, M.T. and Li, Q.Y. (2015) Parthenolide Could Become a Promising and Stable Drug with Anti-Inflammatory Effects. Natural Product Research, 29, 1092-1101. https://doi.org/10.1080/14786419.2014.981541 
[5] Kalia, M., Yadav, V.K., Singh, P.K., et al. (2018) Exploring the Impact of Parthenolide as Anti-Quorum Sensing and Anti-Biofilm Agent against Pseudomonas aeruginosa. Life Sciences, 199, 96-103. https://doi.org/10.1016/j.lfs.2018.03.013

[6] Wiedhopf, R.M., et al. (1973) Tumor Inhibitory Agent from Magnolia grandiflora (Magnoliaceae). I. Parthenolide. Journal of Pharmaceutical Sciences, 62, 345. https://doi.org/10.1002/jps.2600620244

[7] Li, X.H., Xiao, T., Yang, J.H., et al. (2018) Parthenolide Attenuated Bleomycin-Induced Pulmonary Fibrosis via the NF- $\kappa \mathrm{B} /$ Snail Signaling Pathway. Respiratory Research, 19, 111. https://doi.org/10.1186/s12931-018-0806-Z

[8] Liu, M, Bi, H., Hu, L.H., et al. (2018) Parthenolide Inhibits STAT3 Signaling by Covalently Targeting Janus Kinases. Molecules, 23, 1478.

https://doi.org/10.3390/molecules23061478

[9] Flores-Lopez, G., Moreno-Lorenzana, D., Ayala-Sanchez, M., et al. (2018) Parthenolide and DMAPT Induce Cell Death in Primitive CML Cells through Reactive Oxygen Species. Journal of Cellular and Molecular Medicine, 22, 4899-4912. https://doi.org/10.1111/jcmm.13755

[10] Gao, H.E., Sun, Y., Ding, Y.H., et al. (2017) Antineoplastic Effects of CPPTL via the ROS/JNK Pathway in Acute Myeloid Leukemia. Oncotarget, 8, 38990-39000. https://doi.org/10.18632/oncotarget.17166

[11] Yang, C., Yang, Q.O., Kong, Q.J., et al. (2016) Parthenolide Induces Reactive Oxygen Species-Mediated Autophagic Cell Death in Human Osteosarcoma Cells. CelIular Physiology and Biochemistry, 40, 146-154. https://doi.org/10.1159/000452532

[12] Duan, D.Z., Zhang, J.M., Yao, J., et al. (2016) Targeting Thioredoxin Reductase by Parthenolide Contributes to Inducing Apoptosis of HeLa Cells. The Journal of Biological Chemistry, 291, 10021-10031. https://doi.org/10.1074/jbc.M115.700591

[13] Wu, C.Q., Chen, F., Rushing, J.W., et al. (2006) Antiproliferative Activities of Parthenolide and Golden Feverfew Extract against Three Human Cancer Cell Lines. Journal of Medicinal Food, 9, 55-61. https://doi.org/10.1089/jmf.2006.9.55

[14] Saxena, N, Yadav, P. and Kumar, O. (2013) The Fas/Fas Ligand Apoptotic Pathway is Involved in Abrin-Induced Apoptosis. Toxicological Sciences, 135, 103-118. https://doi.org/10.1093/toxsci/kft139

[15] Guo, X.-X., Li, Y., Sun, C., et al. (2014) p53-Dependent Fas Expression Is Critical for Ginsenoside Rh2 Triggered Caspase-8 Activation in HeLa Cells. Protein \& Cell, 5, 224-234. https://doi.org/10.1007/s13238-014-0027-2

[16] Choudhary, G.S., Al-Harbi, S. and Almasan, A. (2015) Caspase-3 Activation Is a Critical Determinant of Genotoxic Stress-Induced Apoptosis. Methods in Molecular Biology, 1219, 1-9. https://doi.org/10.1007/978-1-4939-1661-0_1

[17] Mao, W. and Zhu, Z. (2018) Parthenolide Inhibits Hydrogen Peroxide Induced Osteoblast Apoptosis. Molecular Medicine Reports, 17, 8369-8376.

[18] Li, X., Yang, H., Ke, J., et al. (2017) Smad4 Re-Expression Increases the Sensitivity to Parthenolide in Colorectal Cancer. Oncology Reports, 38, 2317-2324. https://doi.org/10.3892/or.2017.5929

[19] Talib, W.H. and Al Kury, L.T. (2018) Parthenolide Inhibits Tumor-Promoting Effects of Nicotine in Lung Cancer by Inducing P53-Dependent Apoptosis and Inhibiting VEGF Expression. Biomedicine \& Pharmacotherapy, 107, 1488-1495. https://doi.org/10.1016/j.biopha.2018.08.139

[20] Li, C., Ge, Q., Liu, J., et al. (2017) Effects of miR-1236-3p and miR-370-5p on Activation of p21 in Various Tumors and Its Inhibition on the Growth of Lung Cancer 
Cells. Tumor Biology, 39, 1010428317710824. https://doi.org/10.1177/1010428317710824

[21] Liu, B., Zhou, Z., Zhou, W., et al. (2014) Resveratrol Inhibits Proliferation in Human Colorectal Carcinoma Cells by Inducing G1/S Phase Cell Cycle Arrest and Apoptosis through Caspase/Cyclin-CDK Pathways. Molecular Medicine Reports, 10, 1697-702. https://doi.org/10.3892/mmr.2014.2406

[22] Lin, M., Bi, H., Yan, Y., et al. (2017) Parthenolide Suppresses Non-Small Cell Lung Cancer GLC-82 Cells Growth via B-Raf/MAPK/Erk Pathway. Oncotarget, 8, 23436-23447. https://doi.org/10.18632/oncotarget.15584

[23] Lee, C.H., Yang, J.R., Chen, C.Y., et al. (2019) Novel STAT3 Inhibitor LDOC1 Targets Phospho-JAK2 for Degradation by Interacting with LNX1 and Regulates the Aggressiveness of Lung Cancer. Cancers (Basel), 11.

[24] Bloom, M.J., Saksena, S.D., Swain, G.P., et al. (2018) The Effects of IKK-Beta Inhibition on Early NF-kappa-B Activation and Transcription of Downstream Genes. Cell Signal, 55, 17-25. https://doi.org/10.1016/j.cellsig.2018.12.004

[25] Li, J., Liu, Q., Liu, Z., et al. (2018) KPNA2 Promotes Metabolic Reprogramming in Glioblastomas by Regulation of c-myc. Journal of Experimental \& Clinical Cancer Research, 37, 194. https://doi.org/10.1186/s13046-018-0861-9

[26] Mayank, A.K., Sharma, S., Deshwal, R.K., et al. (2014) LIMD1 Antagonizes E2F1 Activity and Cell Cycle Progression by Enhancing Rb Function in Cancer Cells. Cell Biology International, 38, 809-817. https://doi.org/10.1002/cbin.10266

[27] Qiao, L., Zhang, Q., Zhang, W., et al. (2018) The Lysine Acetyltransferase GCN5 Contributes to Human papillomavirus Oncoprotein E7-Induced Cell Proliferation via Up-Regulating E2F1. Journal of Cellular and Molecular Medicine, 22, 5333-5345. https://doi.org/10.1111/jcmm.13806

[28] Gao, S., Chen, M., Wei, W., et al. (2018) Crosstalk of mTOR/PKM2 and STAT3/c-Myc Signaling Pathways Regulate the Energy Metabolism and Acidic Microenvironment of Gastric Cancer. Journal of Cellular Biochemistry, 38, 809-817.

[29] Shu, F., Zou, X., Tuo, H., et al. (2019) Stathmin Gene Silencing Suppresses Proliferation, Migration and Invasion of Gastric Cancer Cells via AKT/sCLU and STAT3 Signaling. International Journal of Oncology, 54, 1086-1098.

[30] Chen, W., Li, P., Liu, Y., et al. (2018) Isoalantolactone Induces Apoptosis through ROS-Mediated ER Stress and Inhibition of STAT3 in Prostate Cancer Cells. Journal of Experimental \& Clinical Cancer Research, 37, 309.

https://doi.org/10.1186/s13046-018-0987-9 